\title{
The value of thyroperoxidase as a prognostic factor for differentiated thyroid cancer - a long-term follow-up study
}

Yurena Caballero ${ }^{1 *}$, Eudaldo M. López-Tomassetti ${ }^{1}$, Julián Favre1, José R. Santana', Juan J. Cabrera² and Juan R. Hernández ${ }^{1}$

\begin{abstract}
Background: Thyroperoxidase (TPO) is a membrane-bound protein essential for the production of thyroid hormones; because of this, TPO expression may be impaired in selected thyroid diseases. The goal of this study is to analyze TPO immune expression in differentiated thyroid cancer, and to determine whether TPO has any prognostic value.

Methods: A total of 139 patients who required surgery due to a thyroid nodule with signs or symptoms suspicious for malignancy during their physical, ultrasound and/or cytology examination were consecutively selected for the study. A study of TPO immunohistochemical expression was carried out on these patients using the MoAb47 monoclonal antibody. In addition, cell proliferation marker Ki67 and tumor suppressor p53 were also measured for comparison.

Results: A total of 139 cases, 43 benign tumors, 42 papillary carcinomas, 38 follicular carcinomas, 8 undifferentiated carcinomas, and 8 sporadic medullary carcinomas were analyzed. The relationship between TPO expression and disease was statistically significant $(p<0.001)$, and decreased with tumor dedifferentiation extent. Increased TPO expression in benign lesions as compared to decreased expression in papillary carcinomas and undifferentiated tumors is outstanding. Differences in TPO expression were observed in minimally invasive follicular carcinoma (MIFC) compared to widely invasive follicular carcinoma (WIFC). TPO expression decreases in undifferentiated malignancies in contrast with p53 and Ki67 expression, which increases in that setting. TPO, p53 and Ki67 expression was significantly related to TNM stage $(p<0.001)$. Survival rate was $72 \%$ after a 20 -year follow-up, and $100 \%$ for subjects with higher TPO expression.

Conclusions: TPO may be useful in confirming or ruling out benign diseases from differentiated thyroid carcinoma, with the exception of low-risk carcinoma such as MIFC. It could be used as a prognostic factor for differentiated thyroid cancer and patient follow-up, together with other markers.
\end{abstract}

Keywords: Thyroid cancer, Thyroperoxidase, Ki67, p53

\section{Background}

Thyroperoxidase (TPO) is a membrane-bound protein essential for thyroid hormone production, characteristic of functional, normal thyroid cells. TPO expression is considered a thyroid differentiation marker. Qualitative and quantitative alterations in TPO activity, TPO messenger ribonucleic acid (mRNA), and protein expression can be related to thyroid changes and have been reported

\footnotetext{
* Correspondence: yure_hop@hotmail.com

${ }^{1}$ General Surgery Department, Hospital Universitario Insular de Gran Canaria, Las Palmas de Gran Canaria, Las Palmas, Spain

Full list of author information is available at the end of the article
}

in pathological thyroid tissues [1]. TPO content has been shown to be significantly lower in thyroid malignancies as compared to benign conditions and normal tissue [2]; also, a reduction in TPO activity and TPO mRNA of 55$70 \%$ is observed in differentiated thyroid carcinoma (DTC) [1, 3]. Moreover, anaplastic tumors have nonexistent TPO expression. The biological meaning of this abnormal TPO expression is unclear; however, a deregulation of protein synthesis can be related. A progressive decrease in TPO levels, together with increased cell density, suggests an association with proliferation.

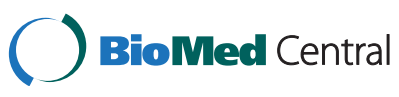

(c) 2015 Caballero et al. Open Access This article is distributed under the terms of the Creative Commons Attribution 4.0 International License (http://creativecommons.org/licenses/by/4.0/), which permits unrestricted use, distribution, and reproduction in any medium, provided you give appropriate credit to the original author(s) and the source, provide a link to the Creative Commons license, and indicate if changes were made. The Creative Commons Public Domain Dedication waiver (http://creativecommons.org/publicdomain/zero/1.0/) applies to the data made available in this article, unless otherwise stated. 
Molecular tests are emerging that measure different gene and protein combinations that may differentiate benign lesions from DTC [4-6]. Although these studies have shown good results and can be promising for the future, these techniques are not readily available in every hospital. On the other hand, immunohistochemistry techniques could be an easier option to differentiate between benign thyroid lesions and DTC.

Many studies have described immunohistochemical markers that improve the diagnosis of thyroid conditions such as TPO on their own or, alternatively, associated with other markers such as galectine-3, CK19, HBME-1, etc. De Micco determined that anti-TPO antibody MoAb47 recognized TPO expression in normal and benign thyroid tissues, but only in $3 \%$ of malignant tumors [7]. TPO gene and protein expression in thyroid carcinoma have been analyzed, indicating low enzymatic activity [2], impaired solubility and suppressed TPO mRNA expression [8]. Savin et al. studied the value of TPO combined with galectine-3 in DTC, observing that TPO had an intense expression in normal or hyperplasic thyroid tissue, and was down-regulated in thyroid pathologies. They reported an inverse correlation with known prognostic factors and TNM staging [9]. However, other reports have obtained the same TPO expression in both benign thyroid diseases and DTC [10].

This study analyzes the immunohistochemical expression of TPO (using MoAb-47) in both benign and malignant lesions to establish the relationship between TPO expression, histological type, differentiation degree, and tumor growth. In malignancies, including both differentiated and undifferentiated cancers; a comparative analysis of TPO with proliferation factor Ki67 and cell-cycle suppressor protein $p 53$ was carried out [11-13].

\section{Methods}

Patients with thyroid nodules and signs or symptoms suspicious for malignancy during physical, ultrasound and/or cytology examination who required surgery during the period 1972 to 1995 were consecutively selected for this study. The ethical approval and informed consent of patients were obtained (The institutional review board was approved by the committe of the Hospital Universitario Insular de Gran Canaria and the University of Las Palmas of Gran Canaria). The institutional review board was approved by the committe of the Hospital Universitario Insular de Gran Canaria and the University of Las Palmas of Gran Canaria. Only 139 cases were included as we had a limited number of monoclonal antibodies available for the TPO immunohistochemical study. Data was prospectively collected and patients were divided into four groups according to their histological diagnosis: benign cases, papillary thyroid carcinoma (PTC), follicular thyroid carcinoma (FTC), and a fourth group called "others", which included undifferentiated thyroid carcinomas and sporadic medullary carcinomas. Specific variants were included in the study, such as the follicular variant of papillary carcinoma and Hürthle cell carcinoma for the PTC group, clear cells and insular pattern for the FTC group. Even though sporadic medullary carcinomas are related to C-cells (and therefore to calcitonin levels) they were not excluded, as we wanted to evaluate TPO, $p 53$ and ki67 expression.

\section{Histological analysis}

After gross examination, the specimens were fixed in $10 \%$ formaldehyde and embedded in paraffin. Blocks were cut using a Leica microtome into 4-5 micron sections, and then studied with several staining techniques (Harris or Mayer hematoxylin, eosin, PAS).

\section{Immunohistochemistry}

The antibodies used for the immunohistochemical study included MoAb-47 for TPO, DO-7 for p53, and Ki67 -MM1 against antigen Ki67.

Once obtained, histology blocks were placed in the heater for twelve hours at $37{ }^{\circ} \mathrm{C}$ and then soaked in xilol three times over $15 \mathrm{~min}$, twice in absolute alcohol over $10 \mathrm{~min}$, once over $5 \mathrm{~min}$ in $96 \%$ alcohol, once in $70 \%$ alcohol, and lastly once time during $5 \mathrm{~min}$ in distilled water. Afterwards, all slides were placed in a pressure cooker with citrate buffer solution as a recovery antigenic system. A process to inhibit endogenous peroxidase using $250 \mathrm{ml}$ of $30 \%$ hydrogen peroxide with $10 \mathrm{ml}$ of methanol during $10 \mathrm{~min}$ followed this. Antibody solutions were prepared with the following dilutions: TPO 1:50, p53 1:50, and ki67 1:100; these were maintained at a temperature of $4{ }^{\circ} \mathrm{C}$ during the staining process. Then we started the incubation process without washing the slides with the primary antibody during $1 \mathrm{~h}$, with the secondary antibody during another hour, and with the avidinbiotin-peroxidase complex during $30 \mathrm{~min}$.

In the final stage, slides were washed in PBS for $15 \mathrm{~min}$ with agitation, and subsequently developed with chromogenic substrate for 3 to $6 \mathrm{~min}$ away from direct light (diaminobenzidine $[\mathrm{DAB}]$ solution); then they were washed with tap water for 5 min 3 times, and contrasted with Harris' or Mayer's hematoxylin for $1 \mathrm{~min}$; finally they were dehydrated using a growing alcohol series (70 \%, $96 \%$, and $100 \%$ twice, and xylol clearing solution twice), and eventually mounted with coverslips using DPX).

Routine techniques such as Congo red under polarized light and calcitonin immunohistochemistry were used for sporadic medullary carcinomas.

\section{Immunohistochemistry assessment}

TPO expression was measured under a light microscope, in terms of percentage of stained cells and stain intensity, using different scores. For the percentage of stained cells an Arabic number was given: 0, 1-10\% stained cells $=1,10-33 \%=2,33-66 \%=3,>66 \%=4$; and for stain intensity: negative $=0$, mild $=1$, moderate $=2$, 
intense $=3$. Intensity and proportion of stained cells were summed using the Vargas-Roig method [14] in order to obtain a single result. Thus, a tumor with a total result of $0-2$ was classified as negative, one with $3-4$ as mild positive, one with 4-5 moderately positive, and one with 5-7 as intensely positive. One pathologist, who was blinded to cytology results, was in charge of the immunohistochemical expression measurement. Separately, another pathologist studied the surgical specimen and provided a final histological diagnosis. The scoring was performed with blinding to patient outcome.

Furthermore, mean, standard deviation, and $95 \%$ confidence interval values were found for each area, both regarding percentage and intensity. The morphological aspects of immunostains were also described for the different pathologies. Overall survival was analyzed according to TPO level and TNM stage, as well as disease-free survival. Disease-free survival was considered for DTC when there was no clinical evidence of tumor, no imaging evidence of tumor, and undetectable serum thyroglobulin levels during TSH suppression and stimulation in the absence of interfering antibodies. For medullary thyroid carcinoma, calcitonin serum levels and carcinoembryonic antigen (CEA) levels were tested every 6 months during the first year, and then annually with an imaging procedure for control.

\section{Statistical analysis}

Data was analyzed using the SPSS v. 18.0 software. Statistical techniques included Pearson's squared chi test for the study of association between categorical variables; Student's $t$-test in the comparison of means for normally distributed numerical variables; Wilcoxon's non-parametric test in case of non-normality; a binary logistic regression model to find parameter profiles and TPO, Ki67, and $p 53$ values; and a Cox proportional hazard analysis for assessing the effect of each prognostic factor on overall survival. A significance level of $5 \%(p<0.05)$ was established for all tests.

\section{Results}

This series includes a total of 139 cases, 43 benign and 96 malignant, classified in four groups. Table 1 summarizes the histological diagnoses by group. The surgical procedures performed included lobectomies, subtotal thyroidectomies (this type of procedure was carried out in patients from 1972 to 1995), and total thyroidectomies.

The immunohistochemical expression of TPO, p53 and Ki67 by disease is detailed in Figs. 1 and 2. TPO expression related to histological diagnosis was statistically significant $(p<0.001)$, with expression decreasing with cellular dedifferentiation. TPO staining patterns were also found in the different groups.
Table 1 Diagnosis by group

\begin{tabular}{|c|c|c|}
\hline Group & & Number (N) \\
\hline \multirow[t]{8}{*}{ Benign } & Nodular hyperplasia & \\
\hline & - Multinodular & 10 \\
\hline & - Uninodular & 9 \\
\hline & Chronic thyroiditis & \\
\hline & - Hashimoto & 7 \\
\hline & $\begin{array}{l}\text { - Chronic nonspecific } \\
\text { lymphocytic thyroiditis }\end{array}$ & 3 \\
\hline & Adenoma & 16 \\
\hline & Total & 43 \\
\hline \multirow[t]{3}{*}{ Papillary carcinoma } & Papillary Carcinoma & 38 \\
\hline & Follicular variant & 4 \\
\hline & Total & 42 \\
\hline \multirow[t]{6}{*}{ Follicular carcinoma } & Widely invasive & 28 \\
\hline & - Clear cells & 2 \\
\hline & - Hürthle cells & 2 \\
\hline & - Insular pattern & 5 \\
\hline & Minimally invasive & 10 \\
\hline & Total & 38 \\
\hline \multirow[t]{3}{*}{ Other } & Undifferentiated carcinoma & 8 \\
\hline & Sporadic medullary carcinoma & 8 \\
\hline & Total & 16 \\
\hline
\end{tabular}

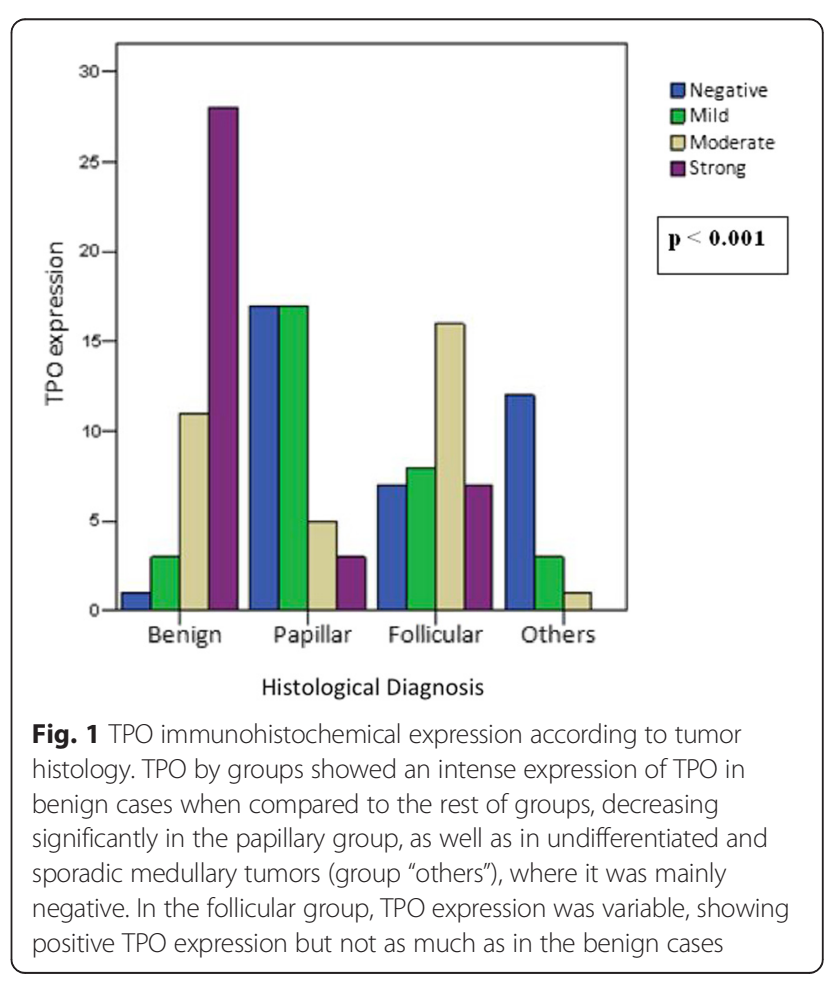




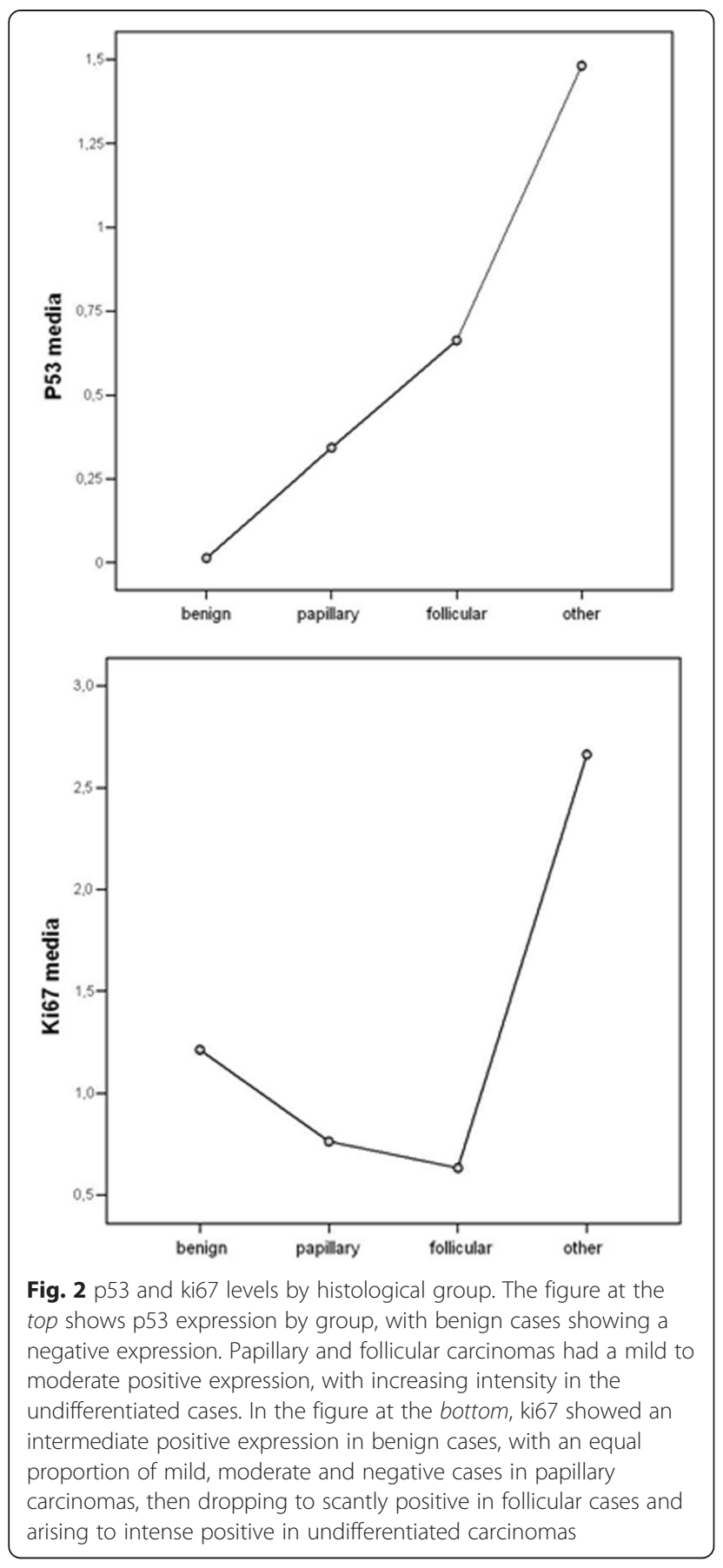

\section{Benign pathology}

In multinodular hyperplasia TPO was consistently positive in the cytoplasm (TPO staining scores: 2.7-5.5), with an irregular distribution highly intense in small follicles with apical TPO concentrations (Fig. 3). Uninodular cases showed moderate to high immunostaining (3.9 to 6.0) in the cytoplasm, particularly in microfollicular areas with cytoplasmic granules, as may be expected from a benign disease. A direct association between TPO intensity, presence of microfollicles, and localization in

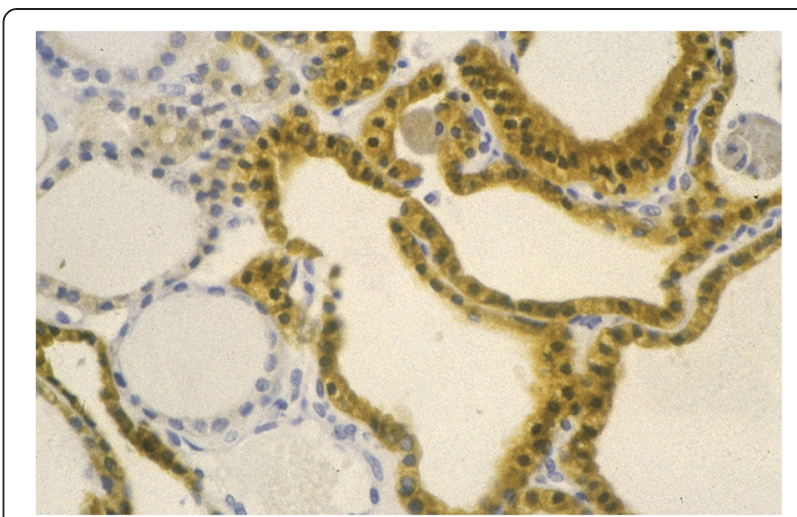

Fig. 3 Multinodular hyperplasia: Nodular hyperplasia showing cytoplasmic TPO expression (TPO ×20) - highly intense in small follicles and apical areas

areas near the capsule was found. In contrast, $p 53$ and Ki67 expression was mostly negative.

TPO expression was moderate to high in all adenomas (mean 4.5), regularly distributed in the cytoplasm with a marked apical predominance. In Hürthle-cell adenomas low TPO positivity is characteristic both in central and subcapsular follicles; positivity is only outstanding for papillary growth patterns. The histological study of $p 53$ was negative in all but two cases - microfollicular and embryonic types. Ki67 expression had intermediate positivity (1.2 to 2.4 ) in normal follicular, microfollicular and Hürthle-cell adenomas, with higher levels in a trabecular adenoma.

\section{Papillary thyroid carcinoma}

TPO staining was usually poor to moderate $(<3)$ in $81 \%$ of cases - higher TPO scores were only seen in four patients (3.6 and 6) - with positive expression in the apical pole of cells in the cystic epithelium and negative expression in Psammoma bodies (Fig. 4b). In follicular variants, negativity was seen in most fields except for focal areas with a regular and patchy distribution.

Protein p53 had mild to moderate staining overall, and Ki67 showed an equal distribution of mild, moderate and negative staining.

\section{Follicular thyroid carcinoma}

TPO results revealed positivity with irregular expression in most cases. Minimally invasive follicular cases (MIFC) (3.5 and 4.9) showed greater TPO immunostaining as compared to widely invasive follicular cases (WIFC) (1.4 and 2.9), with the presence of extensive, totally negative areas in contrast to their neighboring lesion zones (Fig. 4a). Five cases were totally negative. FTC showed decreased TPO immunostaining, both in intensity and percentage, when compared to hyperplasia and, to a lesser extent, thyroid adenoma. These lesions had an 


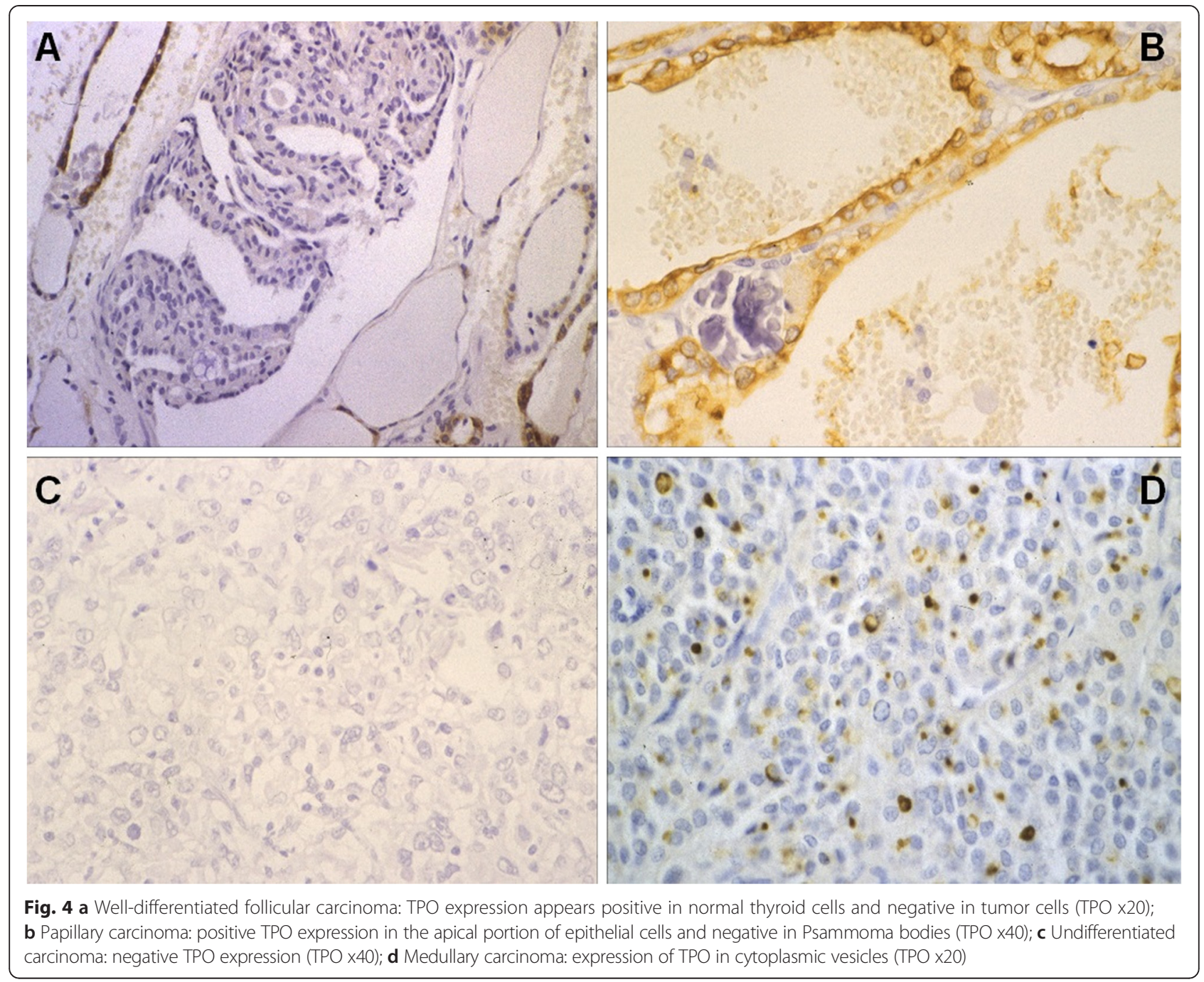

irregular and cytoplasmic TPO stain, with mild and intense areas. In MIFCs TPO expression was moderate to intense in the cytoplasm and mild or negative in the nuclei; intracellular distribution was uniform from basal to apical areas. The presence of TPO in infiltrating follicles, including those protruding into the vascular lumen, is interesting. In WIFCs, expression was usually poorer.

P53 was negative for most MIFCs and positive in three Hürthle-cell carcinomas (1.5-3); WIFCs had scant positivity, and both clear-cell and insular-pattern lesions were negative. Ki67 was scarcely positive in both MIFCs and WIFCs (0.4 and 1.3), with insular variants being moderately positive (1.4 and 3.7).

\section{Others}

\section{Non-differentiated carcinoma}

TPO was negative except in one case, which was considered follicular reclassified as anaplastic. P53 positivity was generally intense ( 4 and 6.5), and Ki67 was positive in all cases with variable intensity ( 0.4 and 5.8 ), with anaplastic variants being more intensely positive (Fig. 4c).

\section{Sporadic medullary carcinoma}

TPO was negative in most cases and moderate in three; the presence of TPO in cytoplasmic vesicle-like deposits was noteworthy (Fig. 4d). P53 immunostaining was negative except for two cases where it was markedly weak (0.2), and Ki67 was negative in four cases and mild to moderate in the remaining four $(2$ y 4$)$.

The cancer cohort was classified according to TNM stage. Figure 5 illustrates the association between TPO immunostaining and TNM stage, observing that TPO decreases as TNM increases.

Follow-up was carried out on an outpatient basis by the endocrinologist and the surgeon by way of physical examination, yearly thyroglobulin levels, and ultrasounds for suspected relapse. A maximum follow-up of 20 years was carried out. Minimum and median follow-up was 5 


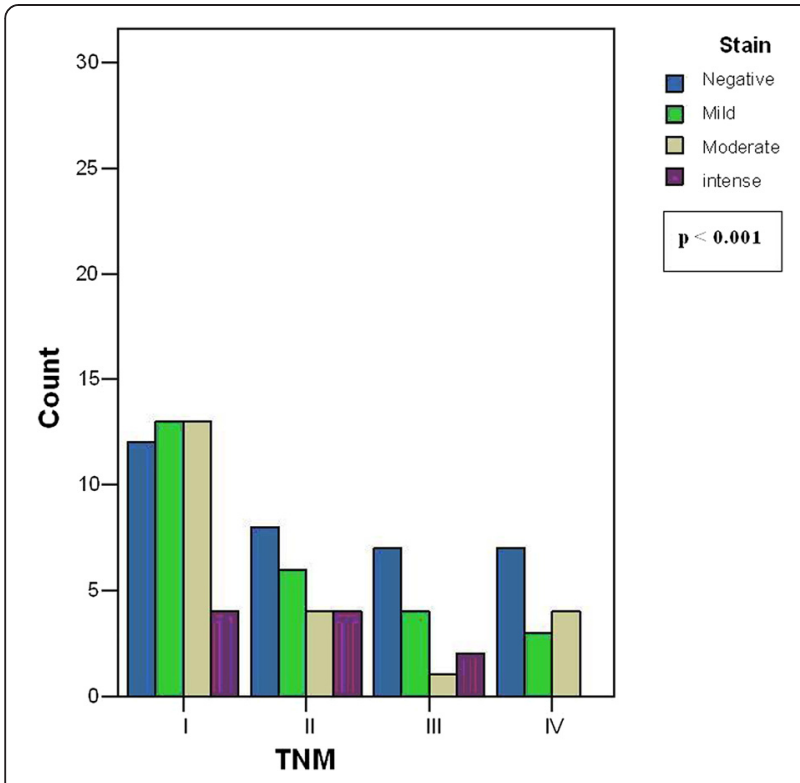

Fig. 5 Relationship between TPO level and TNM stage: The figure shows how TPO expression decreases when TNM increases in terms of intensity, as in stage I more positive than negative cases are found, and in stage II, III and IV more negative than positive cases are observed

and 15 years, respectively. A survival study was carried out, limited to patients with cancer, according to total TPO level (Fig. 6a) and TNM stage (Fig. 6b). Diseasefree survival related to TPO expression (Fig. 6c) and TNM stage (Fig. 6d) was also analyzed.

According to TPO level, overall survival decreased in negative cases compared to positive cases without reaching statistical significance $(p=0.34)$. On the other hand, survival decreased with higher TNM stages $(p<0.001)$, as patients in stage IV had a 20-year survival of $52 \%$ (SD 0.18 ) compared to patients in stage III and II, who had a 20-year survival of $83 \%$ (SD 0.15) and $90 \%$ (SD 0.09), respectively. We did not find any reason for the different survival rates in stages II and III, as they are differentiated by patient age and tumor size and localization.

Disease-free survival also decreased significantly in cases with higher TNM stages $(p<0.001)$. Patients in stage I had a $95 \%$ disease-free survival after a 20-year follow-up. This rate dropped to $47 \%$ for stage II, where patients under the age of 45 are included without taking into account tumor size or local or distant invasion. Stage III had a $29 \%$ disease-free survival, whereas for stage IV all patients were ill at the end the observation period.

\section{Discussion}

TPO is a membrane-bound protein essential in the production of thyroid hormones. It catalyzes the iodination and coupling of tyrosyl residues to thyroglobulin to form thyroid hormones T3 and T4. TPO expression pattern correlates with thyroid follicular cell function, both at the cytoplasm and apical membrane compartments. Quantitative and qualitative changes are related to hormone biosynthesis abnormalities usually due to thyroid disease. The biological meaning of abnormal TPO expression in thyroid tumors is unclear, but the progressive decrease of TPO levels together with an increase in cell density suggests it is correlated with proliferation [1-3].

Ki67 was used to study the proliferative activity of tumors, which determines their aggressiveness, progression, and metastatic potential. It is a monoclonal antibody that binds an antigen present in proliferating cells, but absent from quiescent cells [11]. On the other hand, gene p53 is a suppressor gene that codes for a $p 53$ protein that plays a role in cell-cycle control, replication, and DNA repair. Mutated p53 accumulates in the nucleus of tumor cells, and is promptly identifiable using immunohistochemical techniques [12, 13].

A huge variety of molecular tests are now available for the measurement of prognostic factors in thyroid carcinoma. Weber [4] identified a 3-gene combination to differentiate follicular adenomas from follicular carcinomas, with $100 \%$ sensitivity and $97 \%$ specificity. Rosen [5] compared gene expression in benign thyroid lesions versus papillary carcinoma, and described a set of 6 genes that predicted pathological diagnosis with $75 \%$ sensitivity and $100 \%$ specificity; Kroll [6] described fusion protein PAX8/ $P P A R-\gamma$ as a marker to distinguish benign from malignant follicular lesions. However, molecular techniques and gene studies are costly and time-consuming procedures that render their routine use difficult.

Our study's approach is different. Using simpler methods, such as immunohistochemistry, we analyzed TPO, p53 and Ki67 expression with the purpose of assessing whether TPO is useful as a prognostic marker by means of a longterm survival study. We have not found any literature describing a single study with such a long follow-up. The relationship between TPO expression and disease was statistically significant $(p<0.001)$ and decreased with tumor dedifferentiation extent. We do not know exactly why TPO is lost or increased according to tumor growth or development, albeit we suspect that differentiation criteria are involved. Increased TPO expression in benign lesions as compared to PTC and undifferentiated tumors is outstanding.

TPO increased in FTC to a lesser extent than in benign lesions, with differences in TPO expression between MIFC and WIFC being consistent with most reported studies [7, 15-17]. However, others such as Savin et al. among 47 cases of FTC observed an overall TPO expression of $78.7 \%$ without correlation with degree of histopathological aggressiveness, as TPO expression in WIFC was not less reactive than in MIFC [9]. Microfollicular 


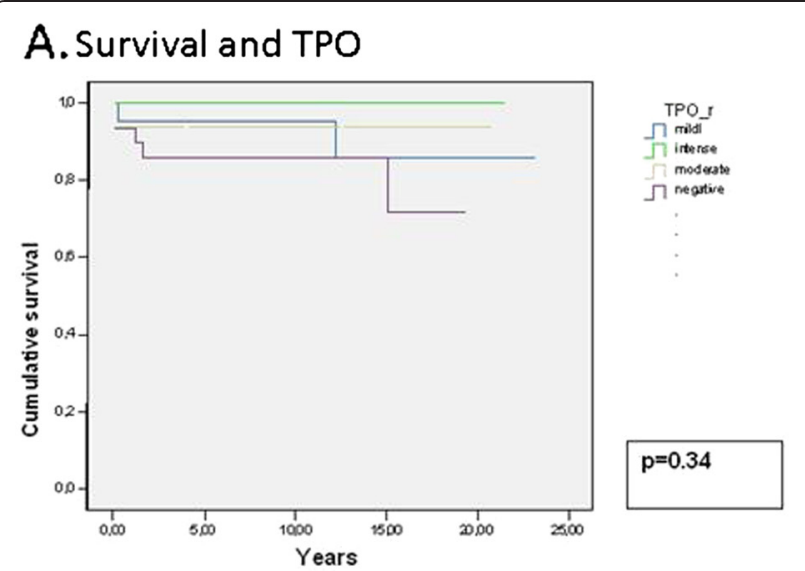

\section{B. Survival and TNM}

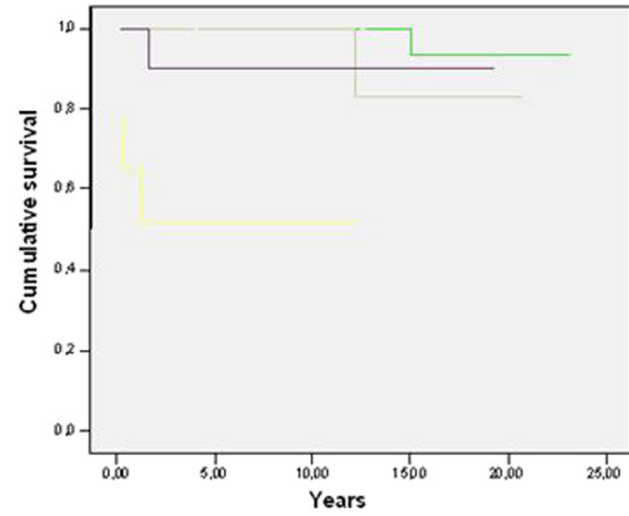

D. Disease Free Survival and TNM

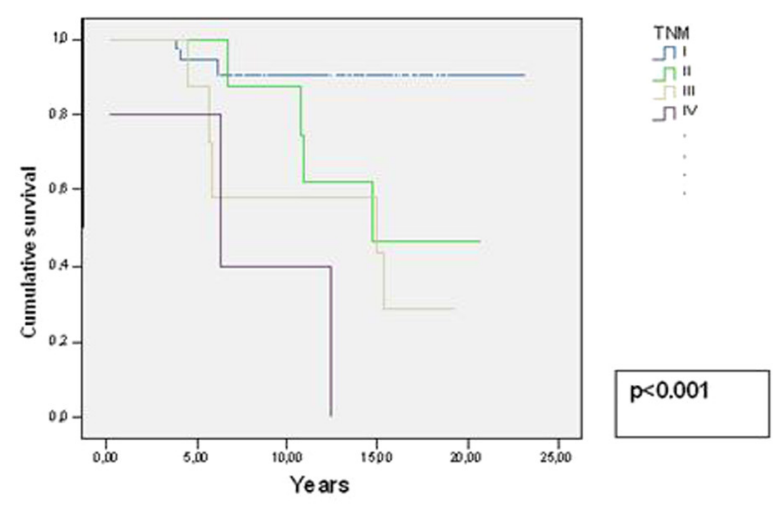

Fig. 6 a Overall survival according to TPO level: overall survival decreases with TPO expression. b Overall survival according to TNM stage: Overall survival decreased with TNM stage, with a 20-year survival of $90 \%, 83 \%$ and $52 \%$ in stages II, III and IV, respectively. c Disease-free survival according to TPO expression: $\mathbf{d}$ Disease-free survival according to TNM stage: The figure shows how disease-free survival (DFS) decreased with TNM stages, with $95 \%$ in stage I, $47 \%$ in stage II, $29 \%$ in stage III, and $0 \%$ in stage IV

adenomas and MIFCs show increased TPO levels, which may reflect a failure of these invasive cells to lose function and differentiation despite their neoplastic course.

In contrast, De Micco [7, 15] observed that immunostaining was irregular in adenomas, moderate in $40 \%$ of the remaining diseases, and negative in follicular carcinomas. This report does not include morphological criteria, immunostaining differences across areas, cytoplasmic localization, intensity assessment, or percentage per histological fields. Weber [4], in a series of 9 FTCs, found that only one was negative, thus reporting high positivity levels and a low sensitivity of TPO for this type of malignancy. In another study, Weber analyzed the use of TPO and galectine-3 separately for the diagnosis and prognosis of thyroid cancer - also combining both markers - and obtained with TPO staining a sensitivity of $39 \%$ for any cancer, of $50 \%$ for PTC, and of $11 \%$ for FTC, which increased with galectine-3 immunostaining to $82 \%, 96 \%$ and $44 \%$, respectively [18]. Therefore, follicular cancer is associated with abnormal TPO expression in studies, with a decrease in TPO immunostaining in $80-95 \%$ of follicular carcinomas.

The scarce TPO staining of PTC in our series is consistent with other reports $[15,19,20]$ that show strong TPO suppression in papillary carcinomas. The negative TPO expression found in undifferentiated carcinomas, where cells lack their endocrine function, supports an association between cell differentiation and TPO levels.

$\mathrm{BRAF}^{\mathrm{V} 600 \mathrm{E}}$ mutation is one of the most common genetic alterations in thyroid carcinogenesis. Its presence in papillary carcinomas has been reported to be associated with advanced stages [21] and poorer clinical outcome, although this remains controversial. Romei et al. analyzed the mRNA expression levels of TPO, among others, according to the presence of $\mathrm{BRAF}^{\mathrm{V} 600 \mathrm{E}}$ mutation [22]. They observed a higher prevalence of the mutation in classical PTC, rather than the follicular variant, and a significantly lower mRNA expression of TPO $(p<0.0001)$ in PTCs with $\mathrm{BRAF}^{\mathrm{V} 600 \mathrm{E}}$ mutation as compared to negative cases, suggesting that $\mathrm{BRAF}^{\mathrm{V} 600 \mathrm{E}}$-mutated PTCs, although still well 
differentiated, are losing the typical features of follicular cells. Therefore, this mutation may be related to an early dedifferentiation process rather than advanced PTC stages. In this study we did not analyze TPO expression according to this mutation; however, we are looking forward to starting a new study in this respect.

TPO expression according to TNM stage shows that TPO substantially decreases when TNM increases. The comparison of mean TPO, Ki67 and $p 53$ values was statistically significant $(p<0.01)$, which corroborates that the immunohistochemical study of TPO has prognostic value, as well as that of Ki67 and p53. However, our results show that an initial analysis of TPO in cytology samples is not effective to distinguish benign from malignant lesions because of TPO expression variability in follicular tumors, consistent with other reports [23, 24]. Nevertheless, TPO may be useful, together with other markers, in confirming or ruling out benign diseases except for low-risk carcinomas such as MIFC.

The relationship between TPO expression and prognosis of thyroid disease has been determined in different studies. Weber, in his 1-year follow-up, observed that $100 \%$ of patients with positive TPO and galectine- 3 immunostaining were free of disease at the end of followup, compared to $57 \%$ of patients with a negative TPO staining. It was suggested that the continued expression of TPO in cancer might predict clinical outcome, rather than the lack thereof [18]. Pulcrano et al. observed that detectable TPO expression was associated with a lower risk of metastasis in a 5-year follow-up, suggesting that persistent functional differentiation reflects a less aggressive behavior [25]. In the present study, overall survival according to TPO expression showed that patients with negative TPO had decreased survival rates, with a cumulative overall survival of 20 years, but the comparison between groups was not statistically significant $(p=$ 0.34). In contrast, survival according to TNM stage was statistically significant $(p<0.001)$. Association between disease-free survival and TPO expression was not significant between groups; however, patients with negative or weak TPO levels had a survival of $72 \%$ and $86 \%$, respectively, in contrast to the 20-year survival rate of $100 \%$ seen with intense TPO expression.

Within the limitations of our study we must underscore the indolent nature of differentiated thyroid cancer and its low mortality rate. Therefore, assessing diseasefree survival is challenging since relapses are usually asymptomatic. Nevertheless, this study has detected significant differences in overall survival according to TNM stage in association with TPO levels, and we believe this is due to our sample size and follow-up length, which reached a maximum of 20 years. Our results should be interpreted cautiously since the study may be influenced by a selection bias, as not all patients in the period referred were included in the study. Lastly, the number of thyroid malignancy samples analyzed is limited, especially when considering the subdivisions included in the classification of thyroid tumors, which may be considered an additional limitation.

\section{Conclusions}

In our study, TPO levels represent a useful prognostic factor for differentiated thyroid cancer. It may be highly useful for patient follow-up. A pronounced TPO fall requires assessment because of a high risk for local and/or distant relapse and decreased survival. The difference in TPO expression between MIFC and WIFC is an interesting finding in this study, and should be considered. In view of our results, TPO cannot be considered an effective diagnostic marker to separate benign from malignant disease following fine-needle aspiration in cases of follicular proliferation $[18,19]$. Further prospective studies are needed.

\section{Abbreviations}

TPO: Thyroperoxidase; DTC: Differentiated thyroid carcinoma; MIFC: Minimally invasive follicular carcinoma; WIFC: Widely invasive follicular carcinoma; mRNA: Messenger ribonucleic acid; PTC: Papillary thyroid carcinoma; FTC: Follicular thyroid carcinoma.

\section{Competing interests}

All authors declare no financial competing interests, nor any other type of conflicts of interest.

\section{Authors' contributions}

CY helped in the acquisition of data and the statistical analysis, reviewed the literature about this topic, and drafted the manuscript. LE and FJ participated in the design of the study, was in charge of the recruitment of patients and data, and revised the manuscript critically. SJ designed the study with $\mathrm{HJ}$, helped in the follow-up of patients, performed the statistical analysis, and took part in the immunohistochemical study of TPO. CJ carried out the immunohistochemical study, took part in the interpretation of data, and helped to draft the manuscript. HJ devised the study, helped to design it, was the main surgeon for patients, and was in charge of follow-up. All authors read and approved the final manuscript.

\section{Author details}

${ }^{1}$ General Surgery Department, Hospital Universitario Insular de Gran Canaria, Las Palmas de Gran Canaria, Las Palmas, Spain. 'Pathology Department, Hospital Universitario Insular de Gran Canaria, Las Palmas de Gran Canaria, Las Palmas, Spain.

Received: 1 June 2015 Accepted: 23 June 2015

Published online: 13 August 2015

\section{References}

1. Valenta $L$, Valenta V, Wang CA, Vickery Jr AL, Caulfield J, Maloof F. Subcellular distribution of peroxidase activity in human thyroid tissue. J Clin Endocrinol Metab. 1973;37:560-9.

2. Mizukami Y, Matsubara F. Correlation between thyroid peroxidase activity and histopathological and ultrastructural changes in various thyroid diseases. Endocrinol Jpn. 1981;28:381-9.

3. Valenta $L$, Meichel-Bechet M. Ultrastructure and biochemistry of thyroid carcinoma. Cancer. 1977;40:284-300.

4. Weber F, Shen L, Aldred MA, Morrison CD, Frilling A, Saji M, et al. Genetic classification of benign and malignant thyroid follicular neoplasia based on a three-gene combination. J Clin Endocrinol Metab. 2005;90:2512-21. 
5. Rosen J, He M, Umbricht C, Alexander HR, Dackiw AP, Zeiger MA, et al. A six-gene model for differentiating benign from malignant thyroid tumors on the basis of gene expression. Surgery. 2005;138:1050-6.

6. Kroll TG. Molecular events in follicular thyroid tumors. Cancer Treat Res. 2004;122:85-105

7. De Micco C, Ruf J, Chrestian MA, Gros N, Henry JF, Carayon P. Immunohistochemical study of thyroid peroxidase in normal, hyperplastic, and neoplastic human thyroid tissues. Cancer. 1991;67:3036-41.

8. Masini-Repiso AM, Bonaterra M, Spitale L, Di Fulvio M, Bonino MI, Coleoni $\mathrm{AH}$, et al. Ultrastructural localization of thyroid peroxidase,

hydrogenperoxide-generating sites, and monoamine oxidase in benign and malignant thyroid diseases. Hum Pathol. 2004;35:436-46.

9. Savin S, Cvejic D, Isic T, Paunovic I, Tatic S, Havelka M. Thyroid peroxidase and galectin-3 immunostaining in differentiated thyroid carcinoma with clinicopathologic correlation. Hum Pathol. 2008;39:1656-63.

10. Ohta K, Endo T, Onaya T. The mRNA levels of thyrotropin receptor, thyroglobulin and thyroid peroxidase in neoplastic human thyroid tissues. Biochem Biophys Res Commun. 1991;14;174:1148-53.

11. Pisani T, Pentellini F, Centanni M, Vecchione A, Giovagnoli MR. Inmunocytochemical expression of Ki67 and laminin in Hürthle cell adenomas and carcinomas. Anticancer Res. 2003:23:3323-6.

12. Dobashi Y, Sakamoto A, Sugimura I, Machinemi R. Overexpression of p53 as possible prognostic factor in human thyroid carcinoma. Am J Surg Pathol. 1993;17:375-81.

13. Soares P, Cameselle-Teijeiro J, Sobrinho-Simões M. Immunohistochemical detection of p53 in differentiated, poorly differentiated and undifferentiated carcinomas of the thyroid. Histopathology. 1994;24:205-10.

14. Vargas-Roig LM, Gago FE, Aznar JC, Ciocca DR. Heat shock protein expression and drug resistance in breast cancer patients treated with induction chemotherapy. Int J Cancer. 1998;79:468-75.

15. De Micco C, Kopp F, Vassko V, Grino M. In situ hybridization and immunohistochemistry study of thyroid peroxidase expression in thyroid tumors. Thyroid. 2000;10:109-15.

16. Garcia S, Vassko V, Henry JF, De Micco C. Comparison of thyroid peroxidase expression with cellular proliferation in thyroid follicular tumors. Thyroid. 1998:8:745-9.

17. Franke WG, Zöphel K, Wunderlich GR, Mat R, Kühne A, Schimming C, et al. Thyroperoxidase: a tumor marker for post-therapeutic follow-up of differentiated thyroid carcinomas? Results of a time course study. Cancer Detect Prev. 2000;24:524-30.

18. Weber KB, Shroyer KR, Heinz DE, Nawaz S, Said MS, Haugen BR. The use of a combination of galectin-3 and thyroid peroxidise for the diagnosis and prognosis of thyroid cancer. Am J Clin Pathol. 2004;122:524-31.

19. Czarnocka B, Pastuszko D, Janota-Bzowski M, Weetman AP, Watson PF, Kemp EH, et al. Is there loss or qualitative changes in the expression of thyroid peroxidase protein in thyroid epithelial cancer? Br J Cancer. 2001;85:875-80.

20. Tanaka T, Umeki K, Yamamoto I, Sugiyama S, Noguchi S, Ohtaki S. Immunohistochemical loss of thyroid peroxidase in papillary thyroid carcinoma: strong suppression of peroxidase gene expression. J Pathol. 1996;179:89-94

21. Namba H, Nakashima M, Hayashi T, Hayashida N, Maeda S, Rogounovitch Tim Ohtsuru A, et al. Clinical implication of hot spot BRAF mutation, V599E, in papillary thyroid cancers. J Clin Endocrinol Metab. 2003;88:4393-7.

22. Romei C, Ciampi R, Faviana P, Agate L, Molinaro E, Bottici V, et al. BRAFV600E mutation, but not RET/PTC rearrangements, is correlated with a lower expression of both thyroperoxidase and sodium iodide symporter genes in papillary thyroid cancer. Endocr Relat Cancer. 2008;15:511-20.

23. Paunovic I, Isic T, Havelka M, Tatic S, Cvejic D, Savin S. Combined immunohistochemistry for thyroid peroxidase, galectin-3, CK19 and HBME-1 in differential diagnosis of thyroid tumors. APMIS. 2012;120:368-79.

24. Savin S, Cvejic D, Isic T, Petrovic I, Paunovic I, Tatic S, et al. Thyroid peroxidase immunohistochemistry in differential diagnosis of thyroid tumors. Endocr Pathol. 2006;17:53-60.

25. Pulcrano M, Boukheris H, Talbot M, Caillou B, Dupuy C, Virion C, et al. Poorly differentiated follicular thyroid carcinoma: prognostic factors and relevance of the histological classification. Thyroid. 2007;17:639-46.

\section{Submit your next manuscript to BioMed Central and take full advantage of:}

- Convenient online submission

- Thorough peer review

- No space constraints or color figure charges

- Immediate publication on acceptance

- Inclusion in PubMed, CAS, Scopus and Google Scholar

- Research which is freely available for redistribution

Submit your manuscript at www.biomedcentral.com/submit 